\author{
Ханс Роберт Мелиг \\ Университет им. Христиана Альбрехта \\ (Германия, Киль) \\ mehlig@slav.uni-kiel.de
}

\title{
ГЛАГОЛЬНЫЙ ВИД И РЕФЕРЕНЦИАЛЬНЫЙ СТАТУС ПРЕДИКАЦИИ: К РАЗЛИЧИЮ МЕЖДУ ОБЩЕФАКТИЧЕСКИМ И ЕДИНИЧНО- ФАКТИЧЕСКИМ НЕСОВЕРШЕННЫМ ВИДОМ В ОТРИЦАТЕЛЬНОМ ОТВЕТЕ НА ВЕРИФИКАТИВНЫЕ ВОПРОСЫ (ДА-НЕТ-ВОПРОСЫ)
}

Предикации с фактическим несовершенным видом (далее - НCВ), во-первых, могут иметь общереферентный статус и отсылать к «типу» (Туре) описываемой ситуации, сообщая, что в течение некоторого временно́го интервала по крайней мере один «экземпляр» (Token), одна ситуация данного типа имела или будет иметь место (общефактический НСВ). Во-вторых, предикации с фактическом НСВ могут отсылать и к конкретной, индивидуализированной ситуации, к «экземпляру» (Token) описываемой ситуации, не представляя ее как происходящую в ее процессуальности (единично-фактический НCB). Общность между общефактическим и единично-фактическим НСВ состоит в том, что в обоих случаях никакая видовая характеристика описываемой ситуации не представлена. Различие между общефактическим и единично-фактическим НСВ является релевантным при отрицательном ответе на экзистенциальные и экспликативные общие вопросы. Экзистенциальные вопросы верифицируют существование описанной ситуации и относятся к модусному компоненту (modus) предикации. Экспликативные вопросы относятся к описанию ситуации, к диктумному компоненту (dictum) и верифицируют правильность обозначения ситуаций, существование которых предполагается. В статье показывается, почему экзистенциальные вопросы в совершенном виде (далее - CB) допускают в ответе отрицание как с общефактическим $\mathrm{HCB}$, так и с единично-фактическим НCB, а экспликативные вопросы - только с общефактическим НСВ.

Ключевые слова: категория вида в русском языке, фактический несовершенный вид, отрицание, экзистенциальные и экспликативные да-нет-вопросы, референциальный статус глагольных предикаций в тексте, тип - экземпляр. 


\section{1. Разграничение общефактического и единично-фактического несовершенного вида}

Предикации с фактическим несовершенным видом (далее - $\mathrm{HCB}$ ) в русском языке допускают две принципиально разные интерпретации. Во-первых, они могут иметь общереферентный статус и отсылать к «типу» (Туре) описанной ситуации. В таком случае они сообщают о том, что в течение некоторого временно́го интервала по крайней мере один «экземпляр» (Token), одна ситуация данного типа имела или будет иметь место. Во-вторых, они могут иметь конкретно-референтный статус и отсылать к одной конкретной, индивидуализированной ситуации, к «экземпляру» (Token) описанной ситуации, не актуализируя ее аспектуальности, т.е. не представляя эту ситуацию в ее процессуальности [Мелиг 2013; Dübbers 2015, Mueller-Reichau 2018]. Обычно эти два варианта фактического НСВ терминологически не различаются. Для обоих вариантов употребляется термин общефактический. Однако различие между этими вариантами фактического НСВ имеет принципиальное значение для категории вида в славянских языках. Поэтому здесь, как и в [Падучева 1996: 43-48], употребляется термин общефактический только для предикаций, которые имеют общереферентный статус и отсылают к «типу» описываемой ситуации. Для предикаций с фактическим НСВ, которые имеют конкретнореферентный статус и отсылают к индивидуализированной, конкретной ситуации, не представляя ее в своем протекании, как происходящую, употребляется введенный А. М. Шелякиным термин единично-фактический [Шелякин 2007] ${ }^{3}$. При этом в отличие от работы Шелякина термин единично-фактический будет здесь использован только для предикаций, которые отсылают к конкретным, индивидуализированным ситуациям ${ }^{4}$. Общность между общефактическим и единично-фактическим НСВ состоит в том, что в обоих случаях ни протекание, ни достижение кульминационной точки описываемой ситуации не актуализуется, никакая видовая характеристика описываемой ситуации не представлена.

Если не знать контекст, то в случае с общим вопросом в НСВ типа Bbl yже передвигали пианино ${ }^{5}$ невозможно определить, имеем мы дело с общефактическим или с единично-фактическим значением НСВ. Если прямое дополнение имеет общереферентный статус, то наш пример допускает только общефактическую интерпретацию. Напротив, если прямое дополнение имеет конкретно-референтный статус и, таким образом, отсылает к определенному пианино, то НСВ допускает обе интерпретации. Общефактическая интерпретация присутствует тогда, когда

3 Е. В. Падучева [1996: 48-52] использует термин акциональное значение НСВ.

${ }^{4}$ А. М. Шелякин [2007] употребляет термин единично-фактический НСВ не только для предикаций с фактическим НСВ, которые описывают конкретные, индивидуализированные ситуации, но также и для предикаций с общефактическим $\mathrm{HCB}$, которые отсылают к типу описываемой ситуации, если они по прагматическим причинам отсылают ровно к одной ситуации описываемого типа, как в примере $T$ bl обедал сегодня?

${ }^{5}$ Малыми прописными буквами обозначается слово, на которое приходится фразовый акцент. 
спрашивается, имело ли место во временно́м интервале, начало которого остается неопределенным и который простирается до момента речи, хотя бы одно передвижение пианино:

\section{(1) Bы когда-нибудь ПЕРЕДВИГАЛИ ваше пианино?}

При этом число ситуаций остается неопределенным. Его можно в дальнейшем контексте уточнить: Да, ПЕРЕДВИГАЛИ, но только раз / даже два раза. При общефактической интерпретации НСВ описание ситуации имеет референциальный статус неспецифической (в другой терминологии - нереферентной) неопределенности. При преобразовании предикации в бытийное предложение номинализованное описание ситуации в артиклевом языке, таком как английский, должно быть введено с так называемым неспецифическим неопределенным артиклем или другим показателем нереферентной неопределенности:

(1a) Has there ever been a movement of the piano?

Предикации с общефактическим НСВ отсылают к типу (type) описываемой ситуации. Отсылка к типу в бытийной парафразе предикации в английском языке может быть маркирована местоимением $s u c h^{6}$, употребляемым в катафорической функции, соответственно в русском языке - местоименным прилагательным такой:

(1б) Такая ситуация, как $\mathbf{X}$, имела место?

Has such a situation as $\mathbf{X}$ taken place?

Отсылка к типу предполагает, что в релевантном пространстве имеется больше чем один «экземпляр» этого типа. Для общефактического НСВ это обозначает, что описываемые ситуации должны быть потенциально повторяемыми, т. е. воспроизводимыми во времени [Шатуновский 2009: 140-147]. В русском языке при отнесенности предикации к типу ситуации допускается употребление только НСВ. Тем самым русский язык отличается, например, от чешского, где при отсылке к типу употребляется как совершенный вид (далее - CB), так и HCB [Dübbers 2015].

Предикации с фактическим НСB, однако, могут отсылать не только к «общим» ситуациям, но и к конкретным, индивидуализированным, не представляя их в своем протекании. В таком случае мы имеем дело с единично-фактическим НСВ. В нашем примере $B b l$ уже передвигали пианино? эта интерпретация НСВ имеет место, если говорящий знает, что у адресата вопроса было намерение переставить пианино, и предикация, таким образом, отсылает к «ожидаемой» ситуации, т.е. к ситуации, которую адресат вопроса может идентифицировать ${ }^{7}$

(2) B В Уже ПЕРЕДВИГАЛИ Пианино, как вы собирались?

${ }^{6}$ О местоимении such 'такой’ как о показателе отсылки к типу см. [Landman, Morzyski 2003].

7 «Эффект ожидаемости» у предикации в СВ подробно описан в [Зельдович 2012: 170-180]. Как показывает наш пример, он может возникнуть и у предикаций в $\mathrm{HCB}$, а именно тогда, когда предикация с единично-фактическим НСВ имеет верификативный коммуникативный статус. 
В такой интерпретации описание ситуации имеет референциальный статус специфической определенности. При преобразовании предикации в бытийное предложение в артиклевом языке, таком как английский, номинализованное описание ситуации должно быть введено с определенным артиклем или другим показателем специфической определенности:

(2a) Has the movement of the piano already taken place?

В русском языке описание ситуации в бытийной парафразе должно образовывать тему бытийного предложения:

Передвижение пианино уже имело место?

При отнесенности нашего примера к «экземпляру», к конкретной, индивидуализированной ситуации русский и чешский языки ведут себя одинаково. В обоих языках может быть употреблен как $\mathrm{CB}$, так и $\mathrm{HCB}$. При употреблении СВ актуализуется достижение внутренней кульминационной точки описываемой ситуации. Спрашивается, достигла ли описываемая ситуация своего результата:

- Вы Уже ПЕРЕДВИнУЛИ ваше пианино?

— Да, ПЕРеДВИнУЛИ и нашли ему хорошее место.

При употреблении единично-фактического НСВ от этой точки абстрагируются, ее достижение оказывается нерелевантным. Вопрос относится не к непосредственному результату описываемой ситуации, а к сопутствующим обстоятельствам:

(2г) - - Вы уже ПЕРедВИГАЛИ ваме пианино, как вы собирались?

— Да, ПЕРЕДВИГАЛИ. Нам ПомогаЛИ СОСЕДИ. / Весь ПоЛ исиарапан.

В отличие от общефактического НСВ употребление единично-фактического НСВ не предполагает, что описываемая ситуация является потенциально повторяемой. Однако имеются ограничения в плане семантики предиката. Единично-фактический НСВ невозможен для предикатов, которые описывают случайные ситуации, «happenings» в классификации Э. Баха [Bach 1986: 6], «pure achievements» в классификации 3. Вендлера [Vendler 1967: 27], например, такие как упасть на улице или потерять пасnорт. Эти предикаты описывают непредвиденные, «неожиданные» ситуации. Поэтому они не допускают ни в русском, ни в чешском языке интерпретации НСВ как единично-фактического. В таком примере, как (3), НСВ может быть проинтерпретирован только как общефактический.

Саша уже терял свой nаспорт?

Как показывает бытийная парафраза, предикация отсылает к типу описываемой ситуации.

Такая ситуачия, как потеря паспорта, уже имелА место? 


\section{2. Разграничение экзистенциальных и экспликативных вопросов}

Глагольные предикации являются бытийными высказываниями. Они содержат двойную информацию. Они сообщают о существовании некоторой ситуации в рамках данного текста и в то же время дают описание ситуации, о существовании которой сообщается. Такое высказывание, как (4), во-первых, сообщает о том, что какая-то ситуация имела место, а во-вторых, описывает эту ситуацию как «передвижение пианино»:

\section{(4) Вчера наши соседи передвигали пиннино.}

Двойная функция финитной формы предиката может быть продемонстрирована через преобразование предикации в бытийное предложение, где информация о существовании ситуации и ее описание даны раздельно:

(4а) Вчера имело место передвижение пиннино.

Ш. Балли [Bally 1950: 39] различает эти два компонента глагольных предикаций терминологически — как modus и dictum, Ч. Филлмор [Fillmore 1968: 23] — как modality constituent и proposition. Верификативные вопросы (да-нет-вопросы) могут относиться как к модусному, так и диктумному компонентам предикации [Мелиг 2008]. Если они относятся к модусному компоненту, то мы имеем дело с экзистенциальным вопросом, или (в другой терминологии) с общим вопросом. Экзистенциальные вопросы верифицируют существование описываемой ситуации в рамках данного текста и в русском языке характеризуются тем, что у них фразовое ударение всегда падает на финитную форму предиката.

Вы вчера ПЕРЕДВИНУЛИ пианино? НАШЛИ ему хорошее место?

Если экзистенциальный вопрос подвергается отрицанию, то мы имеем дело с так называемым общим, в другой терминологии - тотальным, или полным, отрицанием. Общее отрицание имеет экзистенциальное значение. Оно относится к предикативному компоненту предикации. Отрицается существование описываемой ситуации в рамках данного текста:

- Вы вчера ПЕРеДВИНУЛИ пианино?

- Нет еще. Не ПЕРЕДвИНУЛИ.

При общем отрицании в бытийной парафразе предикации отрицательная частица не находится перед бытийным компонентом предикации, в терминологии Ш. Балли — перед модусом:

(5б) Ситуация X не имЕлА места.

Верификативные вопросы, однако, могут относиться и к диктумному компоненту предикации и верифицировать правильность описания ситуации, существование которой предполагается. В таком случае мы имеем дело с экспликативным вопросом, в другой терминологии - с частным, или контрастным, вопросом. Эта 
вторая интерпретация верификативных вопросов для нашего примера иллюстрируется следующими контекстами:

(6) < < вас в комнате стало уютнее. > Вы передвинули пиннино?

(7) <Что это за шум был вчера за стеной?> Соседи передвигали пиннино?

В отличие от экзистенциальных вопросов, в которых фразовое ударение всегда падает на финитную форму предиката, положение фразового ударения в экспликативных вопросах является подвижным. Оно зависит от того, какие компоненты описания известны адресату, а какие - новые. Экспликативные вопросы характеризуются тем, что языковое выражение, на которое падает фразовое ударение, может быть перенесено в позицию перед предикатом.

(7а) <Что это за шум был вчера за стеной?> Соседи пиннино передвигали?

Экспликативные вопросы допускают опровержение посредством так называемого частного, в другой терминологии - противопоставительного отрицания. В отличие от общего отрицания частное отрицание относится не к существованию, а к описанию ситуации.

- Соседи пиАнино передвигали?

- Нет, они не ПиАнино передвигали, а ШкАФ переставляли.

С помощью частного отрицания подтверждается предположение говорящего о существовании ситуации и одновременно корректируется ее описание. Поэтому отрицательная частица не в бытийной парафразе предикации находится не перед бытийным компонентом, а перед описанием ситуации, в терминологии Ш. Балли - перед диктумом.

(7в) Имела место не ситуация $\mathrm{X}$, а ситуация $\mathrm{Y}$.

Экспликативные вопросы допускают и опровержение посредством общего отрицания с последующей корректировкой описания ситуации, как показывает следующий пример:

- Соседи пиннино передвигали?

- Нет, они не передвигали пиАнино. Они ШКАФ переставляли.

\section{3. Употребление вида в отрицательных ответах на экзистенциальные вопросы}

Экзистенциальные вопросы в НСВ допускают отрицательный ответ только в НCB, и это не зависит от того, отсылают они к типу описываемой ситуации, как в примере (8), или к «экземпляру», к ожидаемой ситуации, как в примере (9).

- Саша уже когда-нибудь заполнял анкету для получения визы? Может быть, он знает, как ответить на шестой вопрос?

- Нет, еще не заполнял. Не знает.

( $\rightarrow$ Такой ситуации, как $\mathbf{X}$, еще не было); 
- Саша уже заполнял анкету, которую ему дали в посольстве? Как он ответил на шестой вопрос?

- Он ее ещче не заполнял. Спроси Виктора. Может быть, он ее уже заполнял. $(\rightarrow$ Ситуации X еще не было).

В отличие от этого экзистенциальные вопросы в СВ допускают отрицательный ответ в обоих видах. Как мы видели, экзистенциальные вопросы в СВ всегда отсылают к конкретной, индивидуализированной ситуации, которую адресат, по предположению говорящего, может идентифицировать («эффект ожидаемости»). В таком экзистенциальном вопросе, как Саша зАполнил анкету для получения визы?, описание ситуации имеет референциальный статус специфической определенности. При преобразовании предикации в именное бытийное предложение в артиклевом языке описание ситуации должно быть введено определенным артиклем: Has the situation $X$ taken place? Если экзистенциальный вопрос в СВ отвергается посредством общего отрицания, то возможно употребление как СВ, так и НСВ. При этом НСВ в зависимости от контекста допускает как единично-фактическую, так и общефактическую интерпретацию. Начнем с единично-фактической интерпретации НСВ, которая представлена в следующих примерах:

- Саша зАполнил анкету для получения визы?

- Нет, он ее еще не заполнил/ ещче не заполнял.

- Ты СоКРАТИЛ свою статью?

- Нет ещуе. Не СОКРАТИЛ/ не СОКРАЩАЛ. Но обязательно СОКРАЩУ.

Независимо от употребления видов описание ситуации в отрицательном ответе имеет референциальный статус специфической определенности точно так же, как и описание ситуации в вопросе: The situation X has not yet taken place. Отрицаемые предикации, так же как и вопросы, относятся к преднастоящему (prepresent), т. е. к временно́му интервалу, который простирается до момента речи. Поэтому при переводе на английский язык требуется употребление Present Perfect независимо от того, употребляется СВ или НСВ.

(10a) - Has Sasha filled in the application form for the visa?

- No, he hasn't filled in the form yet.

(11a) - Have you shortened your article?

- Not yet. I haven't shortened it.

В обоих видах отрицаемые предикации сообщают о том, что запрашиваемые ситуации в момент речи не осуществлены. При употреблении союза пока и/или частицы еще сообщается о том, что осуществление ситуации в более позднее время еще возможно, т. е. не исключено после момента речи. Такие предикаты, как заполнить / заполнять анкету и сократить / сокращать статью, являются предикатами accomplishment [Vendler 1967]. В классификации М.Я. Гловинской [2001: 91-100] они принадлежат к первому типу видовой оппозиции. Они описывают ситуации, могущие быть прерванными и реализованными поэтапно. Поэтому имеется четкое семантическое различие между отрицанием с глаголом СВ и с глаголом 
НСВ. При осуществлении отрицания с СВ отрицается только достижение кульминационной точки описываемой ситуации, и без дальнейшего контекста остается открытым вопрос о том, началась уже описываемая ситуация в момент речи или нет. Как показывает пример (12a), отрицательный ответ на вопрос Tbl пРочитАл мою статью? в СВ может отсылать как к ситуации, которая еще не началась, так и к ситуации, уже частично осуществленной:

(12а) Я не ПРочИтАл вашу статью, только начал / даже не начал читать ее.

При отрицательном ответе в НСВ мы имеем дело с единично-фактическим $\mathrm{HCB}$.

- Ты уже ПРОчИТАЛ мою статью?

- Нет, я ее ешіе не читал.

В таком случае никакой видовой характеристики описываемой ситуации нет. Отрицается ее фактичность, а таким образом, и ее процессуальный компонент. Тем самым сообщается о том, что сокращение статьи в момент речи еще не началось. В обоих видах предикация отсылает к конкретной ожидаемой ситуации, на основе контекста не отрицается, что описываемая ситуация в более позднее время может еще состояться.

Единично-фактическое употребление НСВ возможно и тогда, когда предикация относится не к моменту речи, а к другой, указанной в контексте точке отчета, как в следующем примере, где мы имеем дело с предпрошедшим (prepast zone). B английском переводе требуется употребление Past Perfect.

(13) Когда мы приехали, делегаты ещзе не обсудили / обсуждали данный вопрос.

'When we arrived, the delegates had not yet discussed the question'.

И эта предикация отсылает к ожидаемой и, таким образом, индивидуализированной, конкретной ситуации. При отрицании в СВ сообщается, что обсуждение вопроса к моменту нашего приезда еще не достигло своей внутренней кульминационной точки. При этом обсуждение непременно уже началось. При отрицании в НСВ обсуждение вопроса еще не было начато.

Экзистенциальные вопросы в СВ допускают отрицательный ответ с единично-фактическим НСВ и в случае предикатов, которые не имеют процессуального компонента, т. е. тогда, когда мы имеем дело с предикатами, которые 3. Вендлер [Vendler 1967] классифицирует как achievements, Э. Бах [Bach 1986: 6] — как culminations, например заказать / заказывать такси, вызвать / вызывать врача или ответить / отвечать на письмо. В классификации М. Я. Гловинской [2001: 103-107] эти предикаты принадлежат к третьему типу видовой оппозиции.

- Tbl ЗАКАЗАЛ такси?

- Нет еще. Не ЗаказАЛ/ не заКАЗЫВАЛ.

- Саша вызвал врача, как он собирался?

- Нет, пока не вызвал/ пока не вызывал. 


$$
\begin{aligned}
& \text { - Саша ответил на письмо от брата? } \\
& \text { - Нет, еще не ответил / не отВЕЧАЛ. }
\end{aligned}
$$

И в таком случае при отрицании с НСВ никакой видовой актуализации описываемой ситуации не имеется. Отрицание относится к ситуации в целом и, таким образом, к ее возможным предварительным стадиям. Сообщается, что к осуществлению ожидаемой ситуации еще не приступали. Относительно этих предикатов можно при общем отрицании, как предложила Е. В. Падучева [2008: 12], говорить о квазисинонимии между СВ и единично-фактическим НСB, которая отсутствует при опровержении accomplishment-предикатов посредством общего отрицания.

Как мы видели, единично-фактическая интерпретация НCB предполагает, что мы имеем дело с контролируемыми ситуациями. Поэтому такие предикаты, как узнать / узнавать, получить / получать или оставить / оставлять книгу в библиотеке, которые могут описывать как контролируемые, так и неконтролируемые ситуации, при единично-фактическом НСВ обязательно описывают контролируемые ситуации. Это показывает сопоставление примеров (17) и (18):

(17) Саша еще не получал посылку от родителей.

(18) Сама еще не получал пятерку.

Предикат получать посылку в примере (17) описывает контролируемую ситуацию. Поэтому НСВ допускает как общефактическую, так и единично-фактическую интерпретацию. При этом интерпретация зависит от референциального статуса прямого дополнения. Если прямое дополнение имеет общереферентный статус, то предикация относится к типу описанной ситуации и мы имеем дело с общефактическим НСВ.

(17a) Такая ситуация, как X (получение посылки), еще не имела место.

Если же прямое дополнение в примере (17) имеет конкретно-референтный статус и отсылает, например, к посылке от родителей, получение которой ожидается, то и предикация имеет конкретно-референтный статус. Такой предикат, как получать (определенную) посылку, в соответствии с нашим знанием о мире описывает ситуацию с неотменяемым непосредственным результатом [Declerck 2006: 302] - уникальную, неповторимую ситуацию. Одна и та же посылка не может быть получена несколько раз. Поэтому НСВ в этом контексте должен быть проинтерпретирован как единично-фактический. Сообщается, что Саша еще не приступал к получению (определенной) посылки от родителей, т. е. еще не ходил на почту, чтобы ее получить.

(17б) Ситуация $\mathbf{X}$ (получение посылки) еще не имела место.

В отличие от этого НСВ в примере (18) допускает только общефактическую интерпретацию, так как предикат получать пятерку описывает неконтролируемую ситуацию:

(18a) Такая ситуация, как X (получение пятерки), еще не имела место. 
Экзистенциальные вопросы в CB, однако, допускают общее отрицание не только с единично-фактическим НСВ, но и с общефактическим НСВ. Это показывают следующие примеры:

- Tы вчера НАПИСАЛ брату?

- Нет, не пиСАл. Я ему позвонил.

(20) - Ты заКАзАЛтакси?

- Не заказывал. И не буду заказывать: Антон отвезет нас на станиию.

(21) - Сама вызвал врача, как он собирался?

- Знаешь, не вызывал. Решил не вызывать. Больному стало лучше.

- Саша ответилна письмо от брата?

- Нет, не отвечали не будет отвечать. На такие письма не отвечают.

При употреблении общефактического НСВ сообщается о полном отсутствии описываемой ситуации как таковой и тем самым отрицается, что ее осуществление можно еще ожидать в более позднее время. В отличие от единично-фактического НCB предикация с общефактическим НCB отсылает к временно́му промежутку, который разобщен с моментом речи. Поэтому при переводе на английский язык употребляется Simple Tense. При отрицании с общефактическим НCB описание ситуации отсылает к типу описываемой ситуации и имеет референциальный статус неспецифической неопределенности: Tакая ситуация, как $\boldsymbol{X}$, не имелА места. Происходит изменение референциального статуса предикации, а именно переход от специфической определенности в вопросе к неспецифической (нереферентной) неопределенности в отрицательном ответе. Вопрос в СВ имеет конкретно-референтный статус и отсылает к конкретному «экземпляру» ситуации, а отрицательный ответ с общефактическим НСВ имеет общереферентный статус и отсылает к «типу» описываемой ситуации.

Эти две возможности, а именно отсылка предикации с общим отрицанием в НСВ к «экземпляру» или к «типу» описываемой ситуации, имеют соответствие в области именных выражений, где это различие может быть выражено синтаксически, как показывает следующий пример из [Падучева 1985: 107]:

(23) Гостиница не построена.

(24) Гостиницы не построено.

В личном предложении существительное гостиница имеет референциальный статус специфической определенности, и в переводе на английский язык существительное должно быть введено с определенным артиклем:

(23a) The hotel has not been built.

А в безличном предложении существительное имеет референциальный статус неспецифической неопределенности и требует отрицательной формы неопределенного артикля:

(24a) No hotel has been built. 


\section{4. Употребление вида в отрицательных ответах на экспликативные вопросы}

Экспликативные вопросы относятся не к модусному, а к диктумному компоненту предикации. Они верифицируют правильность описания ситуации, существование которой предполагается. В именной парафразе фразовое ударение падает не на бытийный глагол, а на описание ситуации: Какая ситуация имела место? Имела место СИтуАция $Х$ ?

(26) Почему у тебя пальто такое грязное? Ты уПАл?

(27) Где ключ? Ты его ПотеРял?

(28) Где письмо, которое мы вчера получили? Ты его выБРосил?

Экспликативные вопросы, точно так же как и экзистенциальные вопросы, могут отсылать к «типу» и к «экземпляру» описываемой ситуации. В примере (25) описание ситуации имеет общереферентный статус и отсылает к «типу» описываемой ситуации, а в остальных примерах — к конкретным, индивидуализированным ситуациям, к «экземплярам», при этом в примерах (26) и (27) - к случайным ситуациям, к «happenings» в классификации Баха [Bach 1986: 6]. В примере (28) без дальнейшего контекста остается неизвестным, имеем ли мы дело с ожидаемой или случайной ситуацией и - в зависимости от этого - с экзистенциальным или экспликативным вопросом.

Как мы видели, экзистенциальный вопрос в СВ всегда отсылает к ситуации, которую адресат вопроса, по предположению говорящего, может идентифицировать, которую он знает (эффект ожидаемости). Для экспликативных вопросов это неверно. Экспликативные вопросы в $\mathrm{CB}$, точно так же как и экзистенциальные вопросы в $\mathrm{CB}$, отсылают к конкретным, индивидуализированным ситуациям, но в отличие от экзистенциальных вопросов - к ситуациям, которые адресат вопроса не может идентифицировать. В экспликативном вопросе с СВ описание ситуации имеет референциальный статус не специфической о п ре де л ен н о с т и, а специфической н е о п р е д е л е н н о с т и. При преобразовании экспликативного вопроса с СВ в бытийное предложение номинализованное описание ситуации вводится с неопределенным артиклем, см. следующее сопоставление:

1) Экзистенциальный вопрос в СВ: Саша встРетился с Машей? (Встреча с Машей имелА место? 'Has the meeting with Masha taken place?');

2) Экспликативный вопрос в СВ: Откуда Саша об этом знает? Он с МАшей встретился? (Имела место встреча с МАшей? ‘Did a meeting with Masha take place?').

Поскольку в экспликативных вопросах с CB описание ситуации отсылает к ситуациям, которые адресат вопроса не может идентифицировать, в них в отличие от экзистенциальных вопросов могут быть употреблены также предикаты, которые описывают случайные ситуации, см. примеры (26) и (27) выше.

Экспликативные вопросы допускают отрицательный ответ с так называемым частным, противопоставительным отрицанием. Частное отрицание имеет экспликативную функцию, под отрицание попадает только описание ситуации. 
(25a) - Откуда ты об этом знаешь? Ты читал об этом в ГАЗЕТАХ?

- Нет, не в газетах читал, а узнал от Антона.

(26а) - Почему у тебя пальто такое грязное? Ты уПАл?

- Нет, не упал, а к машине твоей прислонился.

(27a) - Где ключ? Ты его потерял?

- Нет, не потерял, а дома забыл.

(28а) — Где письмо, которое мы вчера получили? Ты его выБРосил?

— Нет, не выбросил, а дал прочитать БРАТу.

Посредством частного отрицания подтверждается предположение говорящего, что какая-то ситуация имела место, и одновременно вносится корректировка описания ситуации. В бытийной парафразе отрицательная частица стоит перед описанием ситуации: Имела место не ситуация $X$, а ситуациия $Y$. При частном отрицании никакого изменения вида не происходит. В отрицательном ответе употребляется тот же вид, что и в вопросе.

Однако корректировка описания ситуации экспликативного вопроса также может быть реализована и в два этапа, а именно через предикацию с общим отрицанием и последующую предикацию с правильным описанием ситуации, как показывают следующие примеры:

(25б) - Откуда ты об этом знаешь? Ты читал об этом в ГАЗЕТАХ?

- Нет, я не читал об этом в газетах. Я от Антона узнал.

(26б) - Почему у тебя пальто такое грязное? Ты уПал?

- Нет, я не уПАл. Я прислонился к твоей машине.

(27б) - Где ключ? Ты его ПотЕРял?

- Нет, я его не ПотЕРЯЛ. Я его дома забыл.

(28б) - Где письмо, которое мы вчера получили? Ты его выБРосил?

- Нет, я его не выБРосИл. Я его БРАтУ дал прочитать.

С помощью общего отрицания опровергается существование описанной в экспликативном вопросе ситуации. Затем, в следующем высказывании, происходит нужное исправление посредством высказывания, которое имеет экспликативный статус. Если экспликативный вопрос, как в примере (22), отсылает к типу описываемой ситуации, то в отрицательном ответе возможно употребление только НСВ, поскольку, как мы видели, при отсылке к типу описываемой ситуации употребление СВ исключено. Если же предикации относятся к индивидуализированным, конкретным ситуациям, к «экземплярам» описываемой ситуации, как в примерах (26), (27) и (28), то имеется видовая конкуренция.

Исправление, как показывают приведенные выше примеры, может быть осуществлено посредством общего отрицания в СВ. При общем отрицании в СВ имеется анафорическая отсылка к описанию ситуации, введенной в вопросе, и отрицается ее существование. При этом описания ситуации в вопросе и в ответе имеют один и тот же референциальный статус, а именно статус специфической неопределенности.

Однако корректировка описания ситуации экспликативного вопроса возможна и посредством общего отрицания в $\mathrm{HCB}$, как показывают следующие примеры: 
(26в) - Почему у тебя пальто такое грязное? Ты уПАл?

- Нет, я Не ПАДАЛ. Я к МАШИНЕ ПрИслонился.

(27в) - Где ключ? Ты его ПотЕРЯл?

- Нет, я его не терял. Я его дома забыл.

(28в) - Где письмо, которое мы вчера получили? Ты его выБросил?

- Нет, я его не ВЫБРАСЫВАЛ. Я его БРАТУ дал прочитать.

При употреблении НСВ описание ситуации, введенное в вопросе, повторно упоминается как тип: Такая ситуация, как $\boldsymbol{X}$, не имелА место. Имела место СитуАция $Y$.

В таком случае мы имеем дело с общефактическим НСВ. Происходит изменение референциального статуса описания ситуации, а именно изменение специфической неопределенности в вопросе на неспецифическую неопределенность в ответе. В отличие от экзистенциальных вопросов, у которых в отрицательном ответе возможен как единично-фактический, так и общефактический НCB, НCB в отрицательном ответе на экспликативный вопрос допускает только общефактическую интерпретацию, так как экспликативный общий вопрос отсылает к ситуации, которую адресат вопроса не может идентифицировать.

Отрицание посредством общефактического НСВ может быть усилено путем замены вин. п. прямого дополнения на род. п.

(27г) - Где ключ? Ты его ПотЕРял?

- Нет, не тЕРял я ключа. Я его дома забыл.

(27д) - Где ключ? Ты его ПотЕРял?

- Нет, не теРял я никакого ключа. Я его дома забыл.

Если общее отрицание производится с $\mathrm{CB}$, как в примере (27б), то замена вин. п. на род. п. невозможна, потому что при употреблении СВ между введенным в вопросе референтом и его повторным упоминанием в отрицательном ответе имеется референциальная идентичность. Вопрос и ответ относятся к одному и тому же референту, существование которого в данном дискурсе предполагается.

Корректировка описания ситуации экспликативного вопроса в СВ через общее отрицание с общефактическим НСВ имеет соответствие в области именных выражений, как показывает следующий пример из [Арутюнова, Ширяев 1983: 63]. Такой вопрос, как У тебя в корзине яблоки?, осмысляется благодаря нулевой форме бытийного глагола как экспликативный вопрос. Если на этот вопрос дается отрицательный ответ, то допускается частное (29) и общее (30) отрицание:

(29) У Уеня в корзине не яблоки, а ГриБы.

(30) У Меня в корзине нет яблок. В корзине грибы.

При этом общему отрицанию (30) соответствует в области глагольных предикаций отрицание с общефактическим НСВ. 


\section{Заключение}

В статье разграничиваются экзистенциальные (общие) и экспликативные (частные) верификативные вопросы (да-нет-вопросы). Экзистенциальные вопросы допускают только общее отрицание. Если экзистенциальный вопрос в СВ отрицается ответом с НCB, то НCB может иметь как единично-фактическое, так и общефактическое осмысление. При отрицании с единично-фактическим НСВ ситуация вопроса отсылает, так же как и вопрос в $\mathrm{CB}$, к конкретной ожидаемой ситуации, но без видовой актуализации. Если общее отрицание осуществляется с общефактическим НCB, то имеет место изменение референциального статуса предикации, а именно переход от специфической (референтной) определенности в вопросе к неспецифической (нереферентной) неопределенности в ответе. Отрицается ситуация как тип, как таковая.

В отличие от экзистенциальных вопросов экспликативные вопросы отсылают к описанию ситуации, существование которой предполагается. Они допускают и частное, и общее отрицание. В случае общего отрицания имеется видовая конкуренция, при этом НСВ допускает только общефактическую интерпретацию, поскольку экспликативные вопросы отсылают к ситуациям, которые адресат вопроca, по предположению говорящего, не может идентифицировать.

\section{Литература}

Арутюнова Н.Д., Ширяев Е.Н. Русское предложение. Бытийный тип. М. : Русский язык, 1983. $198 \mathrm{c.}$

Гловинская М. Я. Многозначность и синонимия в видовременной системе русского языка. М. : Азбуковник : Русские словари, 2001. 319 с.

Зельдович Г. М. Прагматика грамматики. М. : Языки славянских культур, 2012. $643 \mathrm{c}$.

Мелиг Х.Р. «Модус» и «диктум» у Ш. Балли // Язык. Культура. Человек : сб. науч. ст. к юбилею проф. М. В. Всеволодовой / ред. М. Л. Ремнева и др. М. : МАКС Пресc, 2008. С. 240-255.

Мелиг X.P. Общефактическое и единично-фактическое значение несовершенного вида в русском языке // Вестник Московского университета. Сер. 9. Филология. 2013. № 4. С. 19-47.

Падучева Е.В. Высказывание и его соотнесенность с действительностью. М. : Наука, 1985. $271 \mathrm{c}$.

Падучева Е.В. Семантические исследования. М. : Языки русской культуры, 1996. $464 \mathrm{c}$.

Падучева Е.В. Имперфектив отрицания в русском языке // Вопросы языкознания. 2008. № 3. С. 3-21.

Шатуновский И. Б. Проблемы русского вида. М. : Языки славянских культур, 2009. $349 \mathrm{c}$.

Шелякин М.А. Категория аспектуальности русского глагола. М. : ЛКИ, 2007. $268 \mathrm{c}$. 
Bach E. The Algebra of Events // Linguistics and Philosophy. 1986. № 9. P. 5-16.

Bally Ch. Linguistique générale et linguistique française. Bern : Francke, 1950. 440 p.

Declerck R. The Grammar of the English Verb Phrase. Vol. 1 : The Grammar of the English Tense System. Berlin ; New York : Mouton de Gruyter, 2006. 846 p.

Dübbers $V$. Konzeptuelle Motivationen des Verbalaspekts und seiner Variationen mit besonderer Berücksichtigung von Iterativität und der „faktischen Funktion“ im Russischen und Tschechischen (unpublished doctoral dissertation). Universität Tübingen, 2015. $451 \mathrm{~S}$.

Fillmore Ch.J. The Case for Case // Universals in Linguistic Theory / ed. by E. Bach, R. T. Harms. London : Holt, 1968. P. 1-88.

Landman M., Morzyski M. Event-Kinds and the Representation of Manner // Proceedings of the Western Conference in Linguistics (WECOL). Vol. 11 / ed. by N.M. Antrim. Fresno : California State University Press, 2003. P. 1-12.

Mueller-Reichau $O$. Das Rätsel allgemeinfaktischer Interpretationen im Aspektsystem des Russischen. Wiesbaden : Harrasowitz, 2018. 200 p.

Vendler Z. Verbs and Times. Linguistics in Philosophy. Ithaca : Cornwell University Press, 1967. P. 97-121.

\author{
Hans Robert Mehlig \\ Christian-Albrecht University \\ (Germany, Kiel) \\ mehlig@slav.uni-kiel.de
}

\title{
VERBAL ASPECT AND THE REFERENTIAL STATUS OF PREDICATIONS: GENERAL FACTUAL AND SINGULAR FACTUAL IMPERFECTIVE ASPECT IN NEGATIVE ANSWERS TO YES-NO QUESTIONS
}

Predications with a factual imperfective aspect may relate to the "type" of the denoted situation and inform us that within a certain time interval at least one "token" of the denoted "type" has occurred or will occur at some point (General-factual ipf. aspect). Otherwise, they can relate to concrete individualized situations without actualization of their aspectuality, i.e. they are not characterized as ongoing (Singular-factual ipf. aspect). This distinction is relevant to the negation of existential and explicative general questions. Existential general questions verify the existence of the denoted situation, whereas explicative general questions verify the correctness of the description of situations whose existence are presupposed. It will be shown that existential questions in the pf. aspect can be negated with both general-factual and singular-factual ipf. aspect. Explicative questions in the pf. aspect can only be negated with the general-factual ipf. aspect.

Key words: verbal aspect in Russian, factual imperfective aspect, negation, existential and explicative questions, referential status of verbal predications, Type - Token reference. 


\section{References}

Arutyunova N.D., Shiryaev E.N. Russkoe predlozhenie. Bytiinyi tip [The Russian Sentence. The Existential Type]. Moscow, Russkii yazyk Publ., 1983, 198 p.

Bach E. The Algebra of Events. Linguistics and Philosophy, 1986, No. 9, pp. 5-16.

Bally Ch. Linguistique générale et linguistique française. Bern, Francke Publ., 1950, 440 p.

Declerck R. The Grammar of the English Verb Phrase. Vol. 1: The Grammar of the English Tense System. Berlin, New York, Mouton de Gruyter, 2006, 846 p.

Dübbers V. Konzeptuelle Motivationen des Verbalaspekts und seiner Variationen mit besonderer Berücksichtigung von Iterativität und der ,faktischen Funktion “ im Russischen und Tschechischen (Dr. phil. sci. diss.). Universität Tübingen, 2015. $451 \mathrm{~S}$.

Fillmore Ch.J. The Case for Case. Universals in Linguistic Theory. E. Bach, R. T. Harms (Eds.). London, Holt Publ., 1968, pp. 1-88.

Glovinskaya M.Ya. Mnogoznachnost' $i$ sinonimiya v vidovremennoi sisteme russkogo yazyka [Ambiguity and Synonymy in the Aspect-Time System of the Russian Language]. Moscow, Azbukovnik Publ., Russkie slovari Publ., 2001, 319 p.

Landman M., Morzyski M. Event-Kinds and the Representation of Manner. Proceedings of the Western Conference in Linguistics (WECOL). Vol. 11. N. M. Antrim (Ed.). Fresno, California St. Univ. Press, 2003, pp. 1-12.

Mehlig H. R. [Ch. Bally's Definition of Modus and Dictum]. Yazyk. Kul'tura. Chelovek: sb. nauch. st. $k$ yubileyu prof. M. V. Vsevolodovoi [Language. Culture. The Human: A Collection of Articles in Honour of M. V. Vsevolodova's Birthday]. M. L. Remneva et al. (Eds.). Moscow, MAKS Press Publ., 2008, pp. 240-255. (In Russ.)

Mehlig H. R. [Singular Factual and General Factual Meanings of the Imperfect Aspect in Russian]. Vestnik Moskovskogo universiteta. Ser. 9. Filologiya, 2013, No. 4, pp. 19-47. (In Russ.)

Mueller-Reichau O. Das Rätsel allgemeinfaktischer Interpretationen im Aspektsystem des Russischen. Wiesbaden, Harrasowitz Publ., 2018, 200 p.

Paducheva E. V. Vyskazyvanie i ego sootnesennost's deistvitel'nost'yu [Utterance and its Correlation to Reality]. Moscow, Nauka Publ., 1985, 271 p.

Paducheva E. V. Semanticheskie issledovaniya [Semantic Research]. Moscow, Yazyki russkoi kul'tury Publ., 1996, 464 p.

Paducheva E. V. [Negation with the Imperfect Aspect in Russian]. Voprosy yazykoznaniya, 2008, No. 3, pp. 3-21. (In Russ.)

Shatunovskii I. B. Problemy russkogo vida [Problems of the Russian Aspect]. Moscow, Yazyki slavyanskikh kul'tur Publ., 2009, 349 p.

Shelyakin M. A. Kategoriya aspektual'nosti russkogo glagola [The Category of Aspectuality of the Russian Verb]. Moscow, LKI Publ., 2007, 268 p.

Vendler Z. Verbs and Times. Linguistics in Philosophy. Ithaca, Cornwell Univ. Press, 1967, pp. 97-121.

Zel'dovich G. M. Pragmatika grammatiki [Grammar Pragmatics]. Moscow, Yazyki slavyanskikh kul'tur Publ., 2012, 643 p. 